\title{
DESAJUSTAMENTO TEMPORAL DA ESCOLA? OS NOVOS PROCESSOS DE SOCIALIZAÇÃO DA GERAÇÃO Z
}

\author{
Carlos Alexsandro de Carvalho Souza ${ }^{1}$
}

\begin{abstract}
Resumo:
Este trabalho teve o objetivo central de apontar e problematizar, a partir de uma abordagem sociológica, algumas das principais tensões que têm sido representativas das atuais relações entre as instituições escolares e alguns indicadores de mudanças comportamentais de jovens da chamada Geração Z. Procurou-se destacar o descompasso entre a manutenção de alguns discursos tradicionais e o caráter institucional da escola e os variados e inéditos estímulos que passaram a condicionar os comportamentos de uma geração de jovens que impõe às escolas novos desafios em relação à sua função social, suas práticas pedagógicas e, sobremaneira, sua relação com outros espaços de socialização. Este estudo concluiu que, diante disso, existem descompassos entre um recorte geracional, suas expectativas, visões de mundo e demandas, considerando, sobretudo, como a literatura especializada delineia-o e a instituição escolar, que se depara com a necessidade de repensar suas práticas e seu lugar nas sociedades contemporâneas.
\end{abstract}

Palavras-chave: Geração Z. Tecnologias digitais. Instituição escolar. Socialização.

1 Doutorando em Sociologia pela Universidade Federal de Sergipe (UFS). Professor de Sociologia o Instituto Federal de Educação, Ciência e Tecnologia de Alagoas (IFAL)

E-mail: c.alexcarvalho@hotmail.com 


\title{
TEMPORAL INADEQUACY OF THE SCHOOL? THE NEW SOCIALIZATION PROCESSES OF GENERATION Z
}

\author{
Carlos Alexsandro de Carvalho Souza
}

\begin{abstract}
:
The main objective of this work is to point out and problematize, from a sociological perspective, some of the main tensions that have been representative of the current relationship between schools and some indicators of behavioral changes in youths of the so-called Generation Z. It seeks to highlight the mismatch between the maintenance of traditional discourse and the institutional character of the school and the varied and unprecedented stimuli that have conditioned the behavior of a generation of young people that imposes on schools new challenges regarding their social function, educational practices and, above all, its relation with other social spaces. This study concludes that there are imbalances between a generation, its expectations, world views and demands, considering, overall, how the specialized literature outlines it and the school, which faces the need to rethink its practices and place in contemporary society.
\end{abstract}

Keywords: Generation Z. Digital Technologies. School. Socialization. 


\section{Introdução}

O objetivo a que se propõe este artigo é bastante modesto: eleger e analisar, a partir de uma incursão temática inicial e da consideração de aportes teóricos, alguns dos fatores que podem ser considerados indicadores empíricos das mais recentes transformações nos processos de socialização dos jovens e de suas consequências no ambiente escolar. Essas transformações, por seu turno, estão relacionadas à substancial expansão do uso das tecnologias digitais e de seus derivados, como computadores, smartphones, tablets e congêneres, e às transformações comportamentais daí decorrentes, como as expectativas e disposições que, na contemporaneidade, os jovens da conhecida Geração Z (TAPSCOTT, 1999) apresentam, reverberando de modo assaz significativo no ambiente escolar.

Os debates e reflexões sobre as transformações geracionais não são novos na literatura especializada em educação, na sociologia da educação ou mesmo na antropologia da educação. O que é inédito e tem demandado incursões teóricas e empíricas são as novas relações entre identidade juvenil, ambiente escolar e o uso de novas tecnologias digitais. O conceito de Geração Z, portanto, torna-se central nesse quadro, já que reúne algumas das principais dimensões indicadoras dos novos processos de socialização nos ambientes digitais e suas reverberações no ambiente escolar. Sabe-se, entretanto, que existem diferentes contextos nos quais agem os jovens da chamada Geração Z, nascidos entre o final da década de noventa e início dos anos 2000, fazendo com que o acesso, a apropriação, a performance e, notadamente, as consequenciais desse processo de manejo das ferramentas tecnológicas e das linguagens digitais se deem de forma diferente, o que abre uma agenda de pesquisas empíricas que podem ser enriquecedoras para o debate.

É possível que o espaço escolar nunca tenha sido ressignificado com tanta intensidade como vem acontecendo atualmente. E isso se deve ao fato de que os jovens estão sendo socializados dentro do que se pode chamar de "sociedade da informação", caracterizada, sobretudo, pela potencialização de acesso às mais variadas fontes de informação, de novas relações com o conhecimento e também pela digitalização, tanto quanto possível, da vida cotidiana, mediante o uso de aparato tecnológico e pela internet. $\mathrm{O}$ que faz com que as mudanças geracionais sejam muito mais intensas e operem em maior extensão do que o foram e operaram no passado recente.

A contemporaneidade, no âmbito das traduções teóricas elaboradas pelas ciências sociais, é caracterizada por um intenso processo de redimensionamentos, remodelações, inconstâncias e tendências intermitentes que têm colocado em cena uma agenda política, educacional e cultural, que tem impactado, decisivamente, não apenas as diversas instituições sociais, dentre as quais, as educacionais, mas também, em sentido mais amplo, as diretrizes comportamentais de um modo geral. Diante desse quadro, as instituições educacionais, como não poderia deixar de ser, não passaram incólumes. 
Em suas múltiplas relações com outras esferas sociais, com o mundo do trabalho, da família, entre outros, revelaram-se novos desafios, além de novas roupagens dos desafios históricos que passam a ser ressignificados, com os quais elas tiveram que lidar para sustentar sua função social diante das expectativas emergentes.

A disseminação das tecnologias, da internet, das redes sociais e dos ambientes virtuais de interação social circunscreve bem uma dimensão temporal em que os diversos processos de socialização dos indivíduos evidenciam uma nova relação com os saberes e os conhecimentos. Desse modo, as instituições educacionais são profundamente impactadas pelas tendências, demandas e expectativas de novas gerações, evidenciando as distintas temporalidades que marcam o universo interno da escola e a historicidade que a ultrapassa, que está além dos seus muros. Ao se atribuir à escola a função de "transferir às gerações mais jovens aqueles saberes e competências estimados e valorizados pelos adultos, permitindo àquelas, acesso às mediações para a sua maturidade na vida social” (DURKHEIM, 2014, p. 10), percebe-se quão central é essa instituição e como ela está inextrincavelmente conectada com as mudanças sociais que lhes são substrato.

Tomando por base a compreensão de que a contemporaneidade está pautada na intensificação das relações sociais, sobretudo porque entrecortada pelos novos ambientes virtuais de interação e pelos variados e sucessivos estímulos que as instituições têm recebido, este trabalho tem o objetivo principal de apresentar um panorama inicial de algumas das tensões que têm indicado os desencaixes entre uma geração que registra a convergência das mudanças acima aludidas e a função social que, tradicionalmente, se atribui às escolas, no plano simbólico e institucional. Busca-se demonstrar como a chamada Geração Z, em sua relação com a escola tradicional, revela tensões que indicam a necessidade de se repensarem as práticas que margeiam a construção dos projetos educacionais e os rumos da educação no Brasil. Uma vez que esses jovens são assediados não apenas por novas tendências comportamentais e estímulos, mas, sobremaneira, pela exigência de novas competências, eles se deparam com novas exigências e demandas por qualificação ou, simplesmente, com justificativas que colocam a escola em condições de concorrência efetiva com as novas formas de excitação das juventudes na era tecnológica. (BARBOSA, 2012)

Deste modo, tem-se um quadro complexo, multifacetado e com múltiplas variáveis que este trabalho não comportará. Tenta-se aqui, portanto, apenas apontar e refletir sobre alguns dos fenômenos que dão contorno aos choques entre, de um lado, uma geração cuja socialização ultrapassa as instituições convencionais e que sofre a influência de uma temporalidade bastante acelerada e, de outro lado, a escola que, como qualquer instituição social, tende a conservar muitos dos pilares sobre os quais se erige. Ela costuma apresentar um tempo-resposta mais lento a estímulos internos e externos, que são mais intensivos, mais contingenciais, mais acelerados e, alguns, até efêmeros, mas não por isso menos sentidos e verificáveis. Decorre daí a necessidade 
de se analisar alguns dos elementos componentes do cenário que se pode chamar de desajustes contemporâneos entre a Geração Z e as instituições escolares.

\section{De onde falamos}

Muitos trabalhos no âmbito da sociologia da educação, principalmente após a difusão dos estudos de Pierre Bourdieu, depois dos anos setenta, debruçaram-se sobre a escola tomando-a como uma instituição de reprodução (NOGUEIRA, 2009). Seja do ponto de vista mais circunscrito aos conteúdos curriculares, colocando a unidade educacional num sistema escalonado e hierarquizado em que o saber produzido nas universidades era transportado para as escolas de educação básica, seja do ponto de vista mais estrutural e sistêmico, aqueles estudos constataram que a escola reproduziria, numa sociedade profundamente estratificada e assimétrica, desigualdades mais amplas. Em função, também, da distribuição desequilibrada de capitais (BOURDIEU; PASSERON, 2014), ela reproduziria as estruturas sociais, garantindo a manutenção de arbitrariedades sob os auspícios de um discurso de democratização do acesso e de redução das desigualdades.

Este último ponto, por seu turno, pode ser desdobrado em, pelo menos, duas perspectivas registradas nos estudos sociológicos sobre a educação: a de um aumento da oferta e ampliação do acesso, e, por outro lado, a alta demanda ainda reprimida e que não conseguia efetivo acesso às escolas. Como o sistema educacional brasileiro é relativamente recente, considerando que, por muitas décadas, houve uma demanda reprimida, demanda essa que, em grande parte desse tempo, sequer possuía amparo constitucional como uma das garantias fundamentais, proliferaram-se reflexões e abordagens, diretamente relacionadas com as supracitadas ou ancoradas em seus múltiplos desdobramentos, construindo uma importante (e permanente) tradição de estudos sobre os sistemas de educação e seus variados componentes, em termos de agência e de estrutura, em suas inumeráveis relações empíricas.

Cumpre notar, também, que alguns trabalhos já se debruçaram sobre as distintas temporalidades que atravessam as instituições escolares, destacando, inclusive, a dimensão da formação das subjetividades dos alunos e dos professores neste ambiente, no intuito de compreender como os processos de ensino e aprendizagem são construídos, reconstruídos e dinamizados pelas práticas dos sujeitos envolvidos no processo. A direção metodológica desses trabalhos está, geralmente, mais circunscrita aos estudos de caso, no interior das escolas, às delimitações de caráter microssocial e com maior interesse pela percepção subjetiva dos atores, característica bastante típica das abordagens compreensivas que privilegiam a ação em detrimento da estrutura. Cada abordagem, à sua maneira, foi fundamental na pavimentação de uma tradição de reflexões nessa seara e abraçaram o desafio de fazê-lo com compromisso e seriedade.

$\mathrm{O}$ último tipo de abordagem mencionado é bastante eficiente quando se considera a tendência de "recobrar o lugar do sujeito nas investigações sobre as instituições 
de ensino.” (CUNHA, 2010, p. 24) O trabalho aqui proposto, no entanto, não faz mais que apontar, no âmbito de sua limitação, elementos estruturais mais amplos e possíveis condicionamentos e tensões de que as unidades de ensino passam a ser objeto. Em função da intensidade e extensão das mudanças, em diferentes dimensões, que caracterizam o que as ciências sociais qualificam como contemporaneidade, resulta realçado, por sua centralidade, o papel social do aluno como partícula empírica de onde parte a reflexão e para onde ela, necessariamente, precisa retornar.

\section{Um breve diagnóstico da contemporaneidade e o lugar ocupado pela escola}

O advento e a disseminação do acesso à internet foram implacáveis, em certo sentido: não significaram apenas uma mudança nos meios técnicos de operação e de comunicação, mas uma transformação robusta no modo como os indivíduos se relacionam uns com os outros e como se relacionam com as instituições sociais que os animam. Nesse turbilhão, a escola, uma das mais prementes instituições, parece receber um duro golpe, se considerarmos o fato de que, como qualquer instituição, ela comporta elementos relativamente refratários às mudanças súbitas, diferentemente do que ocorre em diversas outras esferas sociais de orientação e valoração às quais os indivíduos (na condição de alunos) estão submetidos. Para Zygmunt Bauman (2001), a intensidade da mudança experimentada hoje não encontra paralelo na história humana, e suas consequências nunca foram tão imprevisíveis.

Para esse autor, o elemento mais marcante da liquidez moderna é a fluidez das instituições, ou seja, a perda da capacidade de manter os tradicionais parâmetros de orientação comportamental e de valoração intactos, incólumes às mudanças mais qualitativas e processuais. Registra-se, portanto, um conjunto de desajustamentos na vida dos indivíduos. Por muito tempo resguardados e amparados por aquilo que julgavam sólido, porto seguro, eixos de sustentação da moral, da ética, do saber, esses sujeitos tornam-se agora, em grande medida, objetos de assédio de toda sorte de garantias momentâneas, de soluções efêmeras, de satisfações pontuais, de experiências parciais e, por conseguinte, sentem e representam de modo bastante diferente o mundo que os cercam. Esse é um diagnóstico preliminar indispensável.

A escola, por um lado, foi uma das instituições que sentiu em seu âmago o peso das mudanças. $\mathrm{O}$ aluno, por outro lado, talvez com maior intensidade, delas também foi objeto. Importante considerar, neste momento, a necessidade de qualificar e condicionar a categoria aluno, tão cara às análises sobre os processos educativos escolares, onde quer que sejam feitas. Para considerar o pressuposto fundamental deste trabalho como as mudanças nos processos de socialização mediante a expansão dos ambientes virtuais de interação social criam novos desafios para as instituições escolares - é preciso ter em mente que "aluno” corresponde, num nível aceitável de abstração, à 
parte do indivíduo que está sujeita a um processo de condicionamento e ajustamento pela escola. Em outros termos, a categoria "aluno" compreende apenas um dos papéis sociais desempenhado pelo indivíduo. É possível que o leitor considere isso óbvio, mas esta ressalva é necessária para reforçar o fato de que, através do seu papel de aluno, dentro da escola, o indivíduo veicula, diante das intensas transformações às quais se submete, contemporaneamente, várias expectativas relativas não apenas ao seu status de aluno, mas aos demais papéis que desempenha socialmente. Isso nunca se deu com tamanha clareza e, paradoxalmente, com tanto déficit de explicação, como se pode ver atualmente. Consideremos algumas representações sociais que permeiam essas relações.

Primeiro, a representação da relação entre a escola e o saber tido como socialmente relevante. Por muito tempo, praticamente desde as primeiras tentativas de escolarização promovidas pelos jesuítas, desde o período colonial até algo muito próximo de nossa atualidade, o conjunto de conhecimentos tidos como valiosos, necessários e louváveis esteve restrito a agentes, setores e instituições muito específicas, operando, como se sabe, de forma a manter os abismos sociais que dão o tom dos quadros ainda candentes de uma estratificação social sistemicamente desigual como a brasileira, fazendo da escolarização formal, muito recentemente efetivada (pelos menos no nível normativo e constitucional) como direito universal, um fator de privilégio e barreira por muito tempo intransponível e potencialmente sancionadora das desigualdades.

Nesse quadro, na melhor das hipóteses, a escola era vista como a progenitora do saber, a guardiã dos conhecimentos, numa visão idílica e bastante romântica. Era aquele lugar no seio do qual, de modo inconteste, residiam os conteúdos que atestavam algum tipo de progresso da civilização humana e, por hora o mais importante: uma espécie de monopólio da autoridade do saber. Quando este trabalho se refere ao modelo tradicional de educação, o faz considerando as reminiscências desse passado que ainda perduram nas práticas escolares e, até mesmo, na construção da identidade profissional de muitos docentes.

Os novos meios de difusão da informação, como as plataformas digitais que dão sustentação às redes sociais, aos aplicativos de disseminação de mensagens e seus congêneres, tornaram-se instrumentos que passam a instaurar novos hábitos, comportamentos e concepções de mundo (BARBOSA, 2012), sobretudo por remodelarem as concepções de tempo e espaço e serem responsáveis pela mencionada contestação da escola - e de um grupo específico de seus agentes, os professores - como um lugar saturado, em termos de atratividade e, até mesmo, em quadros avaliativos mais radicais, como uma instituição incapaz de ajudar na formação dos alunos diante dos novos desafios propostos pela vida contemporânea e, sobretudo, pela rapidez com que se processam as mudanças, sejam de ordem profissional e educacional, sejam de ordem afetiva e emocional. 
Não se pode perder de vista o quanto as escolas, dentro de suas históricas limitações estruturais e materiais, vêm tentando estabelecer, até mesmo de modo desesperado, canais de conexão com as recentes demandas “digitais” das novas juventudes. Essa tentativa, entretanto, ainda parece estar circunscrita à dimensão técnica e operacional, ou seja, no nível da tentativa de utilização das conhecidas Tecnologias de Informação e Comunicação (TICs) na sala de aula, sem conseguir, efetivamente, construir um projeto, sistematizado e integrado, de produção de conhecimento, dentro dos novos moldes embebidos pelos ambientes virtuais de interação e de socialização, dandolhes, fundamentalmente, um direcionamento pedagógico e promotor de autonomia e emancipação (HAECHT, 2008; RIBEIRO, 2012). O grande problema, portanto, parece ser a ausência de um direcionamento efetivamente educacional, no sentido de uma concepção de escola concatenada a uma concepção de mundo urdida por novas práticas, expectativas e demandas, onde os jovens são, sem dúvida, os novos protagonistas e parecem não estar mais dispostos a encenar antigos papéis diante dos novos desafios.

Por outro lado, quando se foca apenas no uso dos recursos tecnológicos, sem uma clareza de como eles devem ser inseridos e de como devem promover pontes, seja para a produção de conhecimento renovado, cujo protagonismo é do aluno, para a resolução de problemas concretos, seja para a indicação de novas possibilidades interpretativas e para a tomada de consciência de que são multifacetadas as formas de se compreender e de atuar no mundo em que vivemos (COLL, 2010, p. 83), reforça-se uma visão tecnicista e autocentrada no recurso em si, como se fosse o bastante para contextualizar o aluno e tornar a escola atual e renovada em suas práticas. Isso é perigoso, inclusive, porque pode gerar toda sorte de argumentos para um diagnóstico viciado e deturpado que inscreve o aluno como desinteressado, desestimulado, desmotivado, como se lhe fosse uma característica inata, natural de sua própria condição, de seu papel como aluno, dentro de generalizações recorrentes e facilmente verificáveis. Eis aqui mais um equívoco bastante prejudicial.

Como as demandas dos jovens do século XXI são diagnosticadas pela escola? De que forma elas são filtradas e consideradas na construção dos projetos político pedagógicos? Em que medida, se consideradas, são pensadas como demandas inscritas nas novas formas de socialização das culturas digitais, da instantaneidade e da fluidez que caracterizam a contemporaneidade, pelo menos no âmbito de alguns modelos teóricos? Como os profissionais que fazem a escola a avaliam diante de mudanças tão profundas nas esferas sociais que a permeiam? Como os profissionais da educação expressam suas demandas e suas percepções dessa mudança que afeta, de modo inevitável e sem precedentes, suas práticas profissionais? São questões que gritam por considerações e problematizações, indicando certos aspectos do que alguns cientistas sociais definiram como pós-modernidade e suas variantes, chamando atenção para os novos contornos que delineiam as instituições sociais e sua capacidade de engendrar 
comportamentos, bem como a de serem redesenhadas por eles, no momento atual em que nos encontramos como modelo de sociedade.

Esse é um cenário bastante complexo, pois envolve variados agentes inseridos em diferentes posições sociais, constituindo diferentes hierarquizações e relações de poder, afetados, de modo difuso, por processualidades históricas que questionam suas práticas profissionais e suas metodologias de trabalho tradicionais. A formação de professores, por exemplo, é uma dessas dimensões para as quais se deve olhar com atenção. Os problemas que se registram neste ponto são incontáveis: desde as precárias condições de trabalho em grande parte das unidades educacionais até a baixa remuneração, gerando problemas de diversas ordens, que afetam não apenas os profissionais da educação, mas as instituições educacionais como um todo, considerando, sobremaneira, o aluno como parte inseparável delas.

A literatura especializada aponta variados problemas que caracterizam os sistemas educacionais e comprometem o processo criativo de ensino e aprendizagem, apontando, implícita ou manifestadamente, para um problema sistemicamente maior e que se agrava cada vez mais: a ausência de uma concepção de educação integrada, inclusiva e atenta às transformações do mundo que a cerca com renovadas demandas através do público com que lida: jovens, não de qualquer tipo, mas aqueles cujo ineditismo tem deixado a escola em sérias dificuldades: os jovens da Geração Z, ou denominados nativos digitais (COLL, 2010).

Quais as possibilidades reais, as margens de ação, a capacidade concreta das escolas para atuarem no sentido de filtrar essas demandas e dar-lhes algum encaminhamento? Até que ponto essas cobranças podem ser direcionadas às escolas, tomando-as como responsáveis pela implementação dessas mudanças (ou de partes delas) que se lhes apresentam? É de dentro da instituição escolar que esse olhar deve surgir? São perguntas que sugerem, no mínimo, a necessidade de reflexão sobre os sistemas de ensino como um todo, pois as escolas não podem ser pensadas de modo apartado das políticas educacionais, dos regimes jurídicos e da concepção de sociedade que as ultrapassam. Significam regimes de recursos materiais e financeiros disponíveis ou não para as escolas, garantias constitucionais, estímulos e incentivos à carreira profissional e, sobremaneira, à efetivação ou não de uma democracia cujo cerne seja a inclusão social, a preparação dos jovens para a cidadania plena, o efetivo atendimento das demandas e a clareza quanto à natureza da contemporaneidade.

Os sistemas educacionais, em que a escola está inserida como uma das instituições que os compõem, são muito mais complexos e multifacetados do que podem aparentar, pois, além de revelarem as dimensões acima destacadas, seu formato passa pelo crivo de decisões políticas, essencialmente pautadas pela escolha do que devem, ou não, ser, fazer ou oferecer. Há variáveis estruturais que dão as diretrizes dos sistemas educacionais, em relação às quais as mais distintas realidades educacionais, em 
níveis locais, são forçadas a se adequar, sobretudo porque só desse modo podem, de fato, receber os recursos, validar suas práticas e legitimar a sua existência enquanto unidades educacionais, por exemplo.

Não se pode deixar de considerar que esse modelo hierarquizado e historicamente característico do sistema educacional brasileiro impõe severas limitações diante da distância do seu cume para sua base, diante do que propõe, indistintamente, em uma perspectiva mais generalista, de ordem operacional e burocrática, quando se observam as dinâmicas concretas da realidade orçamentária, do quadro de recursos humanos, das condições estruturais das escolas e a mutabilidade das demandas que os jovens apresentam. Ainda somos um país onde a escolarização de qualidade, inclusiva e democrática, para além das estatísticas e das meras formalidades, ainda é uma promessa, apesar dos inegáveis avanços registrados.

As considerações acima empreendidas, ainda que feitas apenas de modo panorâmico, evidenciam a complexidade do sistema educacional brasileiro. Sugerem também que não se pode atribuir às unidades educacionais a total responsabilidade pela ineficiência em se ajustarem diante de mudanças mais amplas nas instituições que as circundam e que as retroalimentam, como a família, o trabalho e, principalmente, a novas plataformas de socialização, interação e compartilhamento de dados e informações. Falamos de um tempo em que as possibilidades de interação social alargaram-se de modo inimaginável, tomando, aceleradamente, a atenção e a energia dos indivíduos e remodelando, de modo substancial, seus comportamentos e suas visões de mundo. Podemos afirmar que se trata de uma intensificação das relações sociais e de sua potencialização em novas plataformas que são absolutamente contemporâneas, fazendo com que um mundo de fluxos informacionais, interativos e convidativos se abra diante dos indivíduos. São, sem dúvida, à despeito das polêmicas que isso possa suscitar, novos agentes de socialização dos indivíduos. Não se pode desconsiderá-los como tal.

A simultaneidade e a rapidez exigida é um traço dos novos processos de socialização. É comum algo há pouco impossível: conversar com dezenas de pessoas, individualmente ou em grupos, temas diversos, até incompatíveis entre si, concomitantemente. "Abrir janelas”, é uma metáfora bastante conveniente e, nesses ambientes, significa fazer algo que seria empiricamente impossível, do modo como é feito virtualmente. Uma vez nesse ambiente, não se pode ser indiferente a ele: é preciso responder rápido, quando solicitado, compartilhar o máximo possível, estar aqui, ali e em todos os lugares possíveis; nossa existência, o reconhecimento e aprovação social de que necessitamos, diariamente, depende disso. Como desprezar a profundidade dessas mudanças sociais? Como não considerar que uma geração inteira, socializada nesses ambientes, pensa, sente e deseja, se não outras coisas, pelo menos de outra maneira? Esses indivíduos passarão, necessariamente, pela escola. A pergunta é: em que medida a escola também vem sendo produto dessas mudanças, enquanto proponente de novas diretrizes? O que ela pretende fazer diante disso? Temos pensado e agido nesses termos? 
Essas mudanças comportamentais devem ser bem analisadas e devidamente compreendidas, a partir da consideração das causas que as provocam e dos contextos em que se manifestam, para que não se naturalizem certos comportamentos e, em função de deficiências de uma análise mais rigorosa, lhes deem um significado diverso do que de fato podem representar. Frequentemente, surgem relatos de que os jovens estudantes não têm interesse pelas matérias escolares, que não suportam o ambiente escolar, que não conseguem compreender a razão de estar ali e, tampouco, a utilidade que terão, no futuro, aqueles conteúdos que se impõem, arbitrariamente, em sua formação. Esse tipo de relato traz problemas de diversas ordens, como a própria organização curricular, as narrativas de que se serve a escola para se afirmar como instituição social e a própria noção de utilidade que os jovens concebem diante dos novos estímulos a que estão sujeitos nos novos cenários em que estão inseridos. Cada uma dessas dimensões daria um estudo à parte, exigindo dos pesquisadores a canalização de energias e esforços, dada a complexidade de cada uma delas.

O fato é que há um discurso que, nos limites deste trabalho, se pode considerar: a ideia de que "os estudantes não querem nada". Para um efetivo enfrentamento dessa questão, que seja capaz de considerar a função social da escola e os projetos de que ela se serve para efetivar a relação ensino e aprendizagem, essa afirmação, no mínimo, deveria se tornar interrogativa e autodirigida, incorporando mais um elemento: por que os jovens, aparentemente, não querem nada do que está proposto? Nesses termos, a pergunta traz em si uma constatação que deve ser o ponto de partida: algo está proposto e, imediatamente, outra questão se impõe: do que se trata? Em que moldes se apresenta? Finalmente: quais os limites de sua atuação?

\section{Os conflitos geracionais e uma tipificação de referência: a Geração $\mathrm{Z}$ e suas demandas}

Compreender e até mesmo atestar o desinteresse de parte considerável dos alunos é importante, mas não é suficiente ou conclusivo. Na melhor das hipóteses, é apenas preliminar, devendo preceder questões como as mencionadas acima ou as que apontem caminhos complementares possíveis, desde que guiadas pelo interesse de superar suas expressões exteriores, atingindo-lhes o âmago para, só então, construir relações causais empiricamente sustentáveis. Retornamos, então, neste momento, a um ponto fundamental que fora mencionado no início deste trabalho: a ideia de que o aluno com o qual a instituição escolar lida é, substancialmente, influenciado pelos novos ambientes em que está inserido, para além dos muros da escola, isto é, a sua própria condição de aluno, as expectativas que existem em relação a esse papel, sua performance como tal, são dinamizadas por variáveis marcadas pelo ineditismo, em função das mudanças mais amplas pelas quais têm passado os indivíduos, sobremaneira os jovens em formação, já que os novos ambientes virtuais, nos quais, cada vez mais, criam e reforçam seus laços sociais através de formas de interação virtuais, tornaram-se parte 
indissociável de sua própria condição de atores na contemporaneidade.

De que jovens, especificamente, estamos falando? Empreendendo uma tipificação geral, ideal, são categorizados, pela literatura especializada, como Geração Z: jovens que nasceram entre 1995 e 2010, tendo seus processos de socialização e formação de identidade social profundamente condicionados pela presença e pela expansão gradativa da internet, das redes sociais, dos ambientes virtuais de interação social e do contato com os equipamentos tecnológicos, pela digitalização do simbólico, de um modo geral. Alguns analistas, inclusive, optam por categorizá-los como nativos digitais, indicando o fato de que nasceram e cresceram em um tempo-espaço onde as consequências do uso das tecnologias digitais e suas variantes já era uma realidade que não poderia ser desconsiderada como condicionante da formação emocional e comportamental de toda essa geração. É verdade que as categorias e os conceitos que servem para sistematizar elementos difusos encontram, na realidade, em maior ou menor grau, algumas limitações (WEBER, 2001), mas ajudam a compreender os fenômenos a partir do distanciamento que metodologicamente propõem, num primeiro momento do exercício de interpretação.

A ideia de nativos digitais (COLL, 2010), por exemplo, não escapa dessas limitações, sobremaneira porque, embora não se possa negar que a internet e as diversas tecnologias que têm marcado nosso tempo sejam efetivamente condicionantes, do ponto de vista comportamental, elas não operam de modo homogêneo, simultâneo nem geram os mesmos efeitos em realidades sociais tão distintas, principalmente nos recortes da estratificação social brasileira, origem social, escolaridade, renda, entre outros. Os conceitos, como tentativa de formar quadros gerais, são sempre aproximativos e o seu emprego deve ser bastante preciso para que não se percam de vista os seus limites explicativos, evitando naturalizações e equívocos.

Diante disso, a escola depara-se com uma geração que teve suas formas de pensar, sentir e agir remodeladas enquanto fatos sociais e o fator mais decisivo não é, unicamente, em relação ao conteúdo das mudanças, mas, sobretudo, a intensidade, a temporalidade em que elas se processam. Historicamente, muitas mudanças no entorno das instituições escolares exigiram respostas internas adaptativas, no entanto, não parece que nenhuma delas possa ser tomada como parâmetro para o que essas instituições experimentam hoje. Algumas ainda não se deram conta disso; outras tentam procrastinar o enfrentamento do problema. O fato é que ele está aí, impondose e exigindo, ainda que de modo difuso, do ponto de vista de uma agenda política, outros caminhos para guiar as relações entre os jovens e a escola, entre o ensino e a aprendizagem, a partir de competências coerentes com as tendências contemporâneas que os seduzem, que os formam, que lhes dão contornos como indivíduos.

Diante disso, encontra-se uma geração que é provocada e estimulada, cotidianamente, em suas interações sociais, a se relacionar com mediações que são típicas do nosso 
tempo. O uso das já mencionadas ferramentas tecnológicas e da presença em ambientes virtuais de interação social "não pode ser visto apenas como modismo, num sentido depreciativo ou que minimiza seus efeitos sociais, mas como um traço decisivo na formação das identidades de uma geração” (FAVA, 2016), seus sentimentos e suas formas (e meios) de expressá-los, suas percepções de mundo e a capacidade de manejar sua imagem social, cada vez mais solicitada, nos moldes de uma sociedade de consumidores, sobretudo, da própria imagem como elemento de aceitação e reconhecimento social. São essas as condições empíricas no âmbito das quais uma geração lida com os fenômenos entrecortados pelos processos sociais educativos e escolares que lhes impõe uma narrativa de mundo, um conjunto de justificativas e de possibilidades de uso que parece, em função das próprias condições em que se encontra, não ser mais capaz de encontrar algum tipo de adesão ou mesmo coerência com o que é socialmente proposto pelos espaços sociais e simbólicos com os quais as instituições escolares se relacionam.

Trata-se, portanto, de uma geração que passa a enfrentar um "novo dilema em relação ao ofício de aluno” (CUNHA, 2010, p.32), isto é, em relação a todas aquelas competências e expectativas atribuídas ao papel que certos indivíduos desempenham no ambiente escolar: o de aluno. As regras do jogo, no que diz respeito às dimensões curriculares, por exemplo, passam por remodelações decisivas diante das reformas educacionais notadamente marcadas por um discurso estatal de novos tempos e de novas demandas, do mercado de trabalho e da vida social, que não mais se coadunam às prescrições curriculares e de política pedagógica até então executadas. Essa, por si só, é uma dimensão que exige um estudo à parte por sua profundidade e multilateralidade. Cumpre destacar que a Geração Z está submersa nesse turbilhão de projetos de mudança, refletindo um dos traços mais dramáticos da contemporaneidade: múltiplas direções, poucos direcionamentos efetivamente palpáveis, pelo menos se considerarmos a necessária construção democrática que demandam em termos de projetos políticos para a educação.

Quando se fala de processos educacionais, não se pode desconsiderar o fato de que a escola é apenas uma das suas dimensões, embora formalmente a mais decisiva, mas também é necessário acentuar que ela é, acima de tudo, uma instituição de escolarização, isto é, responsável por transmitir aos indivíduos conteúdos, saberes, técnicas e por estimular a construção de competências afetivas e cognitivas que a sociedade, de modo mais ou menos difuso, consagra ou elege como necessárias “para sua própria manutenção sistêmica, daí a necessária e decisiva relação entre as instituições educacionais e condicionantes culturais, políticas e sociais que as atravessam” (TOSCANO, 2004, p. 76), como as já consideradas em parágrafos anteriores. Sendo assim, não só os conteúdos passam por um processo de saturação, mas também algumas das competências que outrora foram tidas como necessárias, já que, olhando para além dos muros da instituição escolar, seriam importantes para 
os desafios da vida.

A formação cidadã e a formação para o mundo do trabalho, por exemplo, sempre estiveram no horizonte dos objetivos de formação que a escola atendia e, em alguma medida, ela nunca perdeu de vista sua conexão com as demandas que a cercavam. Em sua natureza dialética, de modo manifesto ou latente, ela sabia de sua dependência do mundo "lá fora". Cumpre observar, todavia, que o protagonismo juvenil a que assistimos, contemporaneamente, como efeito de uma sociedade de consumidores de produtos, símbolos e perspectivas (BAUMAN, 2008), com a amplificação dos efeitos do capitalismo na vida dos indivíduos e de uma progressiva racionalização do mundo, tomou de assalto as frágeis justificativas nas quais as instituições escolares tradicionais se amparavam diante dos questionamentos que elas passam a sofrer, todos eles inscritos no que se pode chamar de tendências à fluidez, intensidade e instrumentalização da contemporaneidade.

É verdade que nem tudo está muito claramente colocado em debate pelos agentes envolvidos, esse é um ponto decisivo que este trabalho, nos limites de sua modéstia, pretende apontar. Considerar as transformações do modo em que se apresentam não significa que elas sejam, objetivamente, perceptíveis e que se processem do mesmo modo em todos os lugares; que subvertam realidades simplesmente pelo fato de se apresentarem como uma tendência inevitável; que coloquem em xeque e promovam a derrocada total de um modelo de educação, de escolarização e de instituição escolar historicamente construídos; e, sobretudo, que os agentes envolvidos tenham plena consciência da natureza, extensão e intensidade dos processos sociais de remodelação nos quais se inserem e dos quais são produtos, quer queiram ou não.

\section{A necessidade de um protagonismo escolar}

Compreender as processualidades no momento em que acontecem é sempre mais difícil do que analisá-las com certo distanciamento temporal. Eis que é bastante penosa a tarefa das áreas que se debruçam sobre os fenômenos no âmbito da educação, como a sociologia, a pedagogia, a antropologia, entre outras, já que diagnosticar o aqui e agora, empreender um quadro minimamente capaz de indicar o atual estado de coisas é um desafio dos mais complexos. “Ter essas condições em vista é necessário, inclusive, pelo fato de que a teoria social precisa se reencontrar com a arena pública.” (BAUMAN, 2015, p.99) Isto é, ela precisa ser capaz de fornecer intepretações condizentes com os anseios e as múltiplas mutações do nosso tempo que, seja nas instituições, seja nos indivíduos que as animam, estão mutuamente condicionadas, fazem parte da mesma realidade.

Parece-nos urgir, também, a necessidade de diagnosticar, através de uma descrição rigorosa, a real natureza das dificuldades pelas quais as instituições escolares têm passado, notadamente, em relação à sua capacidade operacional de compreender e se 
debruçar reflexivamente sobre as contradições, tensões e descontinuidades geracionais de nossa época (FAVA, 2016). Há muito se sabe que os processos de escolarização são historicamente condicionados e que a escola, como instituição social, repousa em tensões que reproduzem os desajustes sociais decorrentes da dinamização dos fenômenos sociais, cotidianamente e em escala mais ampla. E que a responsabilidade pela formação não apenas escolar, mas também ética, cidadã e profissional, parece ser, cada vez mais, atribuída às escolas, como se tivessem, sozinhas, o dever de atender a todas essas demandas.

As dificuldades contemporâneas pelas quais as escolas passam refletem as dificuldades compartilhadas com várias outras instituições sociais, uma vez que aquele mesmo jovem que traz à tona, no ambiente escolar, novas demandas, sequer minimamente formuladas, às vezes, também as leva ao seio da família, ao ambiente de trabalho, à comunidade religiosa e a tantas outras instituições às quais se vincula. Cumpre observar que não se trata de juízo moral sobre o nosso tempo ou que se conclua, de modo reducionista, que as instituições faliram e que nada se pode fazer. Trata-se, sim, da necessidade de entender as causas das mudanças que assistimos, sua extensão e, sobretudo, como as instituições fundamentais para a modelação comportamental dos jovens, especialmente a escola, devem repensar os meios de que se servem para atingir os fins a que se propõem.

Tradicionalmente, tendências pedagógicas de diversas matrizes são mobilizadas como referências para avaliar alguns dos problemas presentes nos ambientes escolares, no que diz respeito às relações entre ensino e aprendizagem, propondo, em certa medida, uma redenção dos sistemas escolares e fazendo duras críticas, a partir de sua condição de modelos teóricos, às práticas efetivas, situacionais e contingenciais com as quais se deparam essas instituições. $\mathrm{O}$ fato é que sua validade pode correr sérios riscos se se restringem a apontar certos problemas que, no seu pretender, poderiam ser solucionados se lhes fosse aplicada esta ou aquela concepção pedagógica, ultrapassando os limites do caráter de modelo teórico de suas reflexões, numa proposta de instrumentalização pouco eficiente, pois, ao saírem do nível em que são controladas, conceitualmente organizadas, sistematicamente coerentes e com causalidades delimitadas, enfim, enquanto teorias, iriam deparar-se com uma realidade que não se resume a um modelo, sobretudo a um modelo que propõe certas soluções a partir de substituições de procedimentos inscritos na ordem da gestão escolar ou de suas congêneres.

Não se quer dizer que os modelos teóricos não são válidos, sejam da pedagogia ou de qualquer ciência, mas, ao contrário: constituem dimensão fundamental e essencial para as ciências que se propõem a observar e compreender os fenômenos sociais em seu estado real, empírico, delimitando e permitindo alguma sistematização, descrevendo e diagnosticando. Pressupor, todavia, que esses mesmos modelos teóricos (com limitações enquanto tal) possam ser simplesmente transplantados para as instituições e que representem soluções efetivas e convincentes, fazendo crer que basta tomar outras 
orientações, de modo quase mecânico, que está dada a solução, isso é, no mínimo, ingenuidade teórica. Ideais pedagógicos precisam ser vistos como tais: referenciais, ideais que podem ser perseguidos, mas que sempre devem estar condicionados às contingências, nunca depositando neles, à revelia da reflexão dos agentes a que se direcionam (alunos) e dos que os operam (professores e profissionais da educação, conjuntamente), uma fé absoluta. O século XXI parece não mais se convencer de que soluções procedimentais, formais e monolíticas irão responder, com eficiência, problemas e desafios multicausais.

Além dos fenômenos já considerados, ressaltam-se, ainda, outros desafios, ainda mais polêmicos, com os quais as instituições escolares têm lidado na atualidade, o que reforça a necessidade de se refletir sobre os rumos de um modelo de educação e de suas diretrizes e, sobremaneira, diante da relativa autonomia que cada unidade escolar possui, repensar suas práticas, seu projeto institucional e sua capacidade de diagnosticar, com maior rapidez, as dinâmicas que a circundam, considerando, sobremaneira, o fato de que elas são cada vez mais intensas e potencialmente mais impactantes.

Na agenda política que atravessa o debate sobre educação, temos visto vários indicadores de que parte dessa reflexão precisa brotar de dentro para fora, isto é, das realidades particulares, das unidades educacionais, para um sistema educacional, minimizando os seus efeitos homogeneizadores, por sua natureza formal e burocrática. As questões relacionadas às discussões sobre diversidade de gênero, ensino religioso, reformas educacionais, escola sem partido, entre outras, têm evidenciado o quanto é preciso somar esforços para que a escola esteja à frente desses debates, de forma democrática e fazendo valer novos critérios de legitimidade, como autoridade competente, pedagogicamente fundamentada, para dirimir as dúvidas e distorções que esses temas têm produzido, uma vez que estão na ordem do dia e precisam ser discutidos com equilíbrio e tolerância.

A escola não pode ser, diante dos desafios que enfrenta, uma instituição na qual os resultados legislativos sejam incorporados sem a devida relativização, problematização e conscientização, sempre tomando seus fins educacionais como critério de mediação. Resumidamente, a escola não pode perder seu protagonismo quando o assunto é a análise dos diversos temas que afetam a escolarização e suas relações com as demais instituições sociais, de modo a permitir a promoção de ideias de autonomia, de formação cidadã e humana mais coerentes com as demandas que se apresentam na atualidade.

\section{Considerações Finais}

Este trabalho lançou-se ao desafio de apontar algumas das principais mudanças sociais no que concerne, especialmente, à emergência e caracterização da chamada Geração Z e a expansão dos ambientes virtuais de interação social e suas implicações nos ambientes 
escolares. Procurou-se destacar as novas dinâmicas dos contextos nos quais repousam as instituições escolares, considerando que as mudanças geracionais, aliadas a uma inédita profusão de estímulos da internet e das redes sociais, têm sido responsáveis por expressivas mudanças comportamentais nos jovens, exigindo, das escolas, um redimensionamento capaz de, no mínimo, como atividade inicial, diagnosticar esses jovens e compreender que demandas passam a trazer para o ambiente escolar.

Importante destacar a necessidade de construção de projetos educacionais que, nos limites que competem às escolas, efetivamente tornem possível a articulação entre os saberes escolares e as prescrições curriculares e as novas competências exigidas dos jovens nos atuais indicadores estruturais de mudança nos paradigmas das relações entre sujeito e conhecimento e da crise de um modelo tradicional de escola, como apresentado neste trabalho. A Geração Z (e suas múltiplas relativizações, que se dão por fatores geográficos, socioeconômicos, etc.), socializada substancialmente em tempos de disseminação da internet e na oferta amplificada de acesso à informação, parece não mais se ajustar a um modelo de escola cujo projeto pedagógico não comtemple novas competências que passam a ser cobradas desses jovens, o que revela, inclusive, que a temporalidade entre as mudanças no mundo social e a capacidade de ajustamento das instituições escolares nunca foi tão drástica.

É preciso fortalecer e ampliar a agenda de pesquisas sobre os fenômenos dos novos mediadores nos processos de socialização juvenil e sua relação com os limites e possibilidades da construção de projetos pedagógicos capazes de encaminhar as demandas que se apresentam de modo articulado com as prescrições curriculares e, sobretudo, com um projeto de escola capaz de orientar os jovens a enfrentar os desafios pessoais e profissionais que os cenários contemporâneos têm apresentado.

\section{Referências}

BAUMAN, Zygmunt. Modernidade líquida. Rio de Janeiro: Zahar, 2001.

. Vida para consumo: a transformação das pessoas em mercadoria. Rio de Janeiro: Zahar, 2008.

. Sobre educação e juventude. Rio de Janeiro: Zahar, 2013.

. Para que serve a sociologia. Rio de Janeiro: Zahar, 2015.

BARBOSA, Luciana. Juventudes e gerações no Brasil contemporâneo. Porto Alegre: Sulina, 2012.

BOURDIEU, Pierre; PASSERON, Jean. A reprodução: elementos para uma teoria 
do sistema de ensino. Petrópolis-RJ: Vozes, 2014.

COLL, Cezar. Psicologia da educação virtual: aprender e ensinar com as tecnologias da informação e da comunicação. Porto Alegre: Artmed, 2010.

CUNHA, Maria. Sociologia da educação. Belo Horizonte: Editora UFMG, 2010.

DURKHEIM, Emile. Educação e sociologia. Petrópolis-RJ: Editora Vozes, 2014.

FAVA, Rui. Educação para o século XXI: a era do indivíduo digital. São Paulo: Saraiva, 2016

HAECHT, Ana. Sociologia da educação: a escola posta à prova. Porto Alegre: Artmed, 2008.

NOGUEIRA, Alice. Bourdieu e a educação. Belo Horizonte: Editora Autêntica, 2009.

RIBEIRO, Ana. Novas tecnologias para ler e escrever: algumas ideias sobre ambientes e ferramentas digitais na sala de aula. Belo Horizonte: RHJ, 2012.

TAPSCOTT, Dan. Geração digital: a crescente e irreversível ascensão da geração net. São Paulo: Makron Books, 1999.

TOSCANO, Moema. Introdução à sociologia educacional. São Paulo: Editora Ática, 2004.

WEBER, Max. Metodologia das ciências sociais. Vol I. São Paulo: Cortez editora, 2001.

Recebido em: 08/03/2018

Aprovado em: 27/03/2019 